\title{
Good Quality Discussion is Necessary But Not Sufficient in Asynchronous Tuition: a Brief Narrative Review of the Literature
}

\author{
William James Fear \\ Department of Organizational Psychology \\ Birkbeck College University of London \\ Andrew Erikson-Brown \\ Department of Organizational Psychology \\ Birkbeck College University of London
}

\begin{abstract}
The growth of online learning within education has corresponded to an increase in use of asynchronous discussion. Asynchronous discussion is a form of interaction that is mediated rather than directed, and is characterized by a time lag in the interactions between discussants. In this paper we conducted a brief narrative review of the literature on asynchronous discussion. We argue, initially, that discussion is necessary, but not sufficient, for successful pedagogic outcomes-especially in the case of online learning. We identified areas of agreement within the literature on what can be considered the key factors for successful asynchronous discussion.
\end{abstract}

\section{INTRODUCTION}

The use of the Internet to expand distance learning and create non-traditional pathways to Higher Education is expanding rapidly. It is possible to achieve a large range of undergraduate and post-graduate degrees through distance learning that places a high level of reliance on web-based interaction with content, tutors, and peers (fellow students). While higher rated and more strongly accredited qualifications tend to use blended learning, most rely strongly on asynchronous discussion.

In this paper we consider the role of web-based asynchronous discussion as a critical factor of online learning within Higher Education (Cantor, 1992; Dennen, 2005, 2008; Henri, 1995; Kanuka \& Anderson, 1998; Salmon, 2000). We take the position that high quality discussion is a necessary, but not sufficient, factor in producing high level pedagogical outcomes. The 'problem' with asynchronous discussion is precisely that it is asynchronous and lacks the affective immediacy of face-to-face interaction.

The question posed to guide the present review is how instructors can best manage asynchronous discussion. For example: is a high level of lecturer engagement better or worse; how directive should the lecturer be in the discussion; does asynchronous discussion favor the 'sage on the stage' or the 'guide on the side'; and so on (Andresen, 2009; York \& Richardson, 2012).

Given the breadth and general nature of the question, we conducted a narrative literature analysis (Baumeister \& Leary, 1997). To select articles, we focused specifically on those directly related to asynchronous discussion. However, we did not want to be drawn into comparisons and discussion relating to, for example, blended learning and considerations such as the use of additional technologies such as 
Skype and other means of web-based interaction (Brown, 2012; Junk, Deringer \& Junk, 2011; Lim, 2004; McGee \& Reis, 2012).

We will discuss the methodology for the review briefly, and then consider the context and other factors related to our question. We will make the point that the single difference between asynchronous discussion and traditional forms of discussion is the lag in time between interactions and the use of written text-written by students and instructors-rather than verbal components. We then discuss what we found to be the key factors for successful asynchronous discussion noted in the literature. By successful we mean leading to recognizable pedagogical outcomes (Andresen, 2009; Brown, 2012; Crawley \& Fetzner, 2013; Fetzner, 2013; Hew \& Cheung, 2003).

In reviewing the literature we began by reading widely on the topic and learning to identify and select papers that were germane to our questions either in part or whole. We selected reading from mainstream journals that cover asynchronous learning and searched databases such as EBSCO, ERIC, and PSYCHLIT for the term asynchronous discussion/learning. We also sought direction from credible webbased sources such as the Community of Inquiry group, the Sloan Consortium, and the Higher Education Academy. We read until we reached the point where no new information was forthcoming (similar to qualitative saturation), although we recognized that details and nuances continued to emerge. We selected a small body of papers (c. 55 papers excluding grey literature and web-based material, circa 70 including grey literature; not all of these are cited here. Note: Grey literature is defined by the New York Academy of Medicine as "That which is produced on all levels of government, academics, business and industry in print and electronic formats, but which is not controlled by commercial publishers." It is commonly referred to in narrative reviews and includes sources such as include institutional websites, professional level reports, policy documents.) which we felt presented the clearest and most concise answer to our question: what are the core considerations for conducting asynchronous discussion that produces high level pedagogical outcomes? Selection was a matter of personal and professional judgment based on prior reading. This seemed appropriate given we were seeking a 'broad brush answer' to an interesting question and were not attempting to develop theory.

Of course, there is the matter of how to recognize good quality discussion. The literature recognizes success factors such as retention, good grades, high levels of interaction, quality of student interaction (using specific metrics), and so on (Andresen, 2009; Brown, 2012; Crawley \& Fetzner, 2013; Fetzner, 2013; Hew \& Cheung, 2003). This provided a benchmark against which we exercised professional judgment. Papers reporting the means to deliver good tuition were benchmarked against papers that simultaneously report both the means to deliver good tuition as well as success factors. In addition, we selected papers using theories and models to generalize findings (Armstrong \& Thornton, 2012; Kirby, Moore \& Schofield, 1998; Moule, 2007). Once we had a small set of papers with consistency we collated key reported factors and grouped factors accordingly. Once the factors were grouped, they were then summarized. We note that following our approach the factors emerged naturally in much the same way as themes emerge in a thematic analysis or grounded theory approach. The difference here was that we did not need to make a judgment about selecting the factors or naming the factors as they were already identified and named in the literature.

Following this it became apparent that there was an unexpected theme in the literature, particularly for papers in JALN, regarding students' perspectives (Crawley \& Fetzner, 2013; Fetzner, 2013; Parisio, 2011; Vonderwell, 2003). A selection of papers was further culled, and the same process followed, in order to identify the necessary and sufficient factors from students' perspectives. Student success factors for asynchronous discussion tend to be the same as student success factors in face-to-face situations with one exception: in the asynchronous setting there is no way to catch up.

Thus we were able to combine theory driven observation of factors for successful asynchronous discussion in the literature with: a) reported observations of student behavior during successful asynchronous tuition; and b) reported observations from institutions with a record of success in asynchronous tuition (an unexpected finding that emerged during the reading of the papers on student perspectives and behaviors observed in colleges with high retention rates). 


\section{A. Context and other factors}

Many of the principles of asynchronous discussion, the methods of pedagogy, are no different than those for face-to-face discussion (Andresen, 2009; Huang \& Hsiao, 2012; Parisio, 2011; Tu \& Corry, 2003; Vonderwell, 2003) - for example, the use of case studies and collaborative assignments. That is, from a constructivist perspective, we need to provide the structures, activities and guidelines that facilitate learning through student-student interaction. The difference with asynchronous learning is four-fold: 1) clearly, it is not face-to-face; 2) there is a time lag in the interactions; 3 ) interactions take place through the medium of text rather than verbal discourse; and 4) students may be in distant and separate geographical locations. These factors, when combined, create subtle and nuanced distinctions that may not apply, for example, to blended learning scenarios where students have the opportunity, albeit somewhat limited, to interact with faculty and other students.

Equally, there are predictable success factors in the form of, for example, institutional commitment to student success which can be enacted across all facilities and services throughout the institution and owned by key players (Moore \& Fetzner, 2004). Similarly, knowing your students is critical in terms of the characteristics of students attending the institution rather than on a single course.

Some general principles emerged relating specifically to the facilitation of asynchronous discussion in a teaching environment. There are some contradictory findings, such as the debate between keeping the discussion focused and allowing for, and even encouraging, divergent discussion (Beaudin, 1999; Cantor, 1992; Jorczak, 2011; Ugoretz, 2005; Winiecki \& Chyung, 1998), and the number of times either the tutor or student should post each week (Pelz, 2004; Zingaro \& Oztok, 2012). We have not engaged with these debates but have grouped and summarized key factors identified in relation to facilitating discussion as a non-traditional lecturer (NTL).

Arguably the purpose of facilitated discussion in Higher Education is to create a community of inquiry as a means for entry into a community of practice (Kear, 2004). Membership within a community of practice requires familiarity with, and practice in the use of, the artifacts of that community.

One of the key artifacts is vocabulary. Vocabulary allows participants access to shared concepts, meanings, and understandings. Practice with the vocabulary is developed through appropriate discussion and the application of that vocabulary in authentic situations (Kear, 2004; Kirby, Moore \& Schofield, 1998; Moore \& Fetzner, 2004).

The NTL introduces students into the community of practice by facilitating student learning of language, vocabulary, and constructs used by the community of practice. This learning is developed by designing and structuring the space in which a community of inquiry can develop through facilitated peer-peer interaction and task oriented collaboration. A necessary factor for interaction and collaboration is discussion. Intuitively it would seem likely that discussion is potentially more difficult in asynchronous settings because of time delays, lack of access to guardians and gatekeepers, and so on. However, we did not find anything to support this intuition.

Design, strategy, structure and so on all match those for face-to-face with some slight differences largely due to time lag and the physical logistic realities (e.g. you can't get everybody together in the same location at the same time and have a synchronous discussion etc.). Courses and activities should be designed to maximize interaction using a high number of collaborative activities. Emphasis should be placed on their relevance to everyday activity and interaction with other external resources such as websites, YouTube, Twitter, and so on. Problem solving tasks related to course objectives should be used to focus activities.

\section{FACTORS FOR SUCCESSFUL ASYNCHRONOUS DISCUSSION}

\section{A. Presence}

The presence of the NTL is a critical factor in asynchronous discussion, but that presence also needs to be 
restrained (Kear, 2004). This is the same distinction as in face-to-face environments between the 'sage on the stage' and the 'guide on the side' heuristics. Creating an appropriate online presence is balancing act - there is the requirement for a social presence, a cognitive presence, and a teaching presence (Dennen, 2005; Garrison, Cleveland-Innes \& Fung, 2010; Kanuka \& Anderson, 1998; Lee, 2014; Sloane Consortium; Wan, 2008).

Developing a social presence requires the NTL to interact, to bring cohesion to the group, and to express and respond appropriately to expressed emotion. A cognitive presence is developed through the demonstration of factual, theoretical and conceptual knowledge. The teaching presence is probably the most familiar. The NTL facilitates discussion, identifies agreement and disagreement, promotes consensus and understanding, and encourages discussion by acknowledging contributions and drawing in participants. However, a somewhat counterintuitive and uncomfortable position for the NTL is that they should not be drawn into settling debates. Rather, they should set the boundaries, guidelines and rules for discussion but need to allow students opportunities to reach agreement and consensus on their own terms (Andresen, 2009).

\section{B. Threaded posts}

Asynchronous discussion typically takes the form of threaded posts (a topic which has been the subject of some debate). The principles of using threaded posts are the least controversial and most straightforward and the technique of requiring a meaning summary in the subject line is widely supported (Winiecki \& Chyung, 1998). While regular posting is crucial, quality should be encouraged over quantity. That having been said, it has been observed that earlier posts generate more discussion than later posts, but there is no reason to assume this pattern is unique to asynchronous discussion.

\section{Quality posts}

Quality posts are considered those that address course matters, discuss and reflect critically on content, and respond explicitly to comments by other students (Henri, 1995; Salmon, 2000; Zingaro \& Oztok, 2012). Simple, useful rules of posting such as requiring comments to introduce new material and creating a subject field that conveys the essence of the main point have been applied successfully.

Quality posts may also present personal experience relevant to the topic, present examples, and introduce divergence and digression into conversations. The value of divergence is based upon findings that effective peer-to-peer discussion-i.e. leading to learning - requires conceptual conflict and divergence in order to reach consensus (Cantor, 1992; Ugoretz, 2005). This is not unique to asynchronous discussion but is perhaps more visible in such formats. Furthermore, peer-to-peer discussion is more effective than instructor-learner discussion. There is broad agreement that discussion should take the form of student-led conversational dialogue that encourages, and allows for, divergence and digression.

\section{Discussion}

Asynchronous discussion seems to benefit from a conversational style that leads to dialogue, with a high degree of student control including the construction of open-ended questions and discussion topics by students (Kanuka \& Anderson, 1998). That is, the discussion benefits from being student-led.

Similarly to all group work the NTL should initiate discussion to promote student reflection and to initiate and develop relationships within groups and progress to deeper cognitive discussion. This takes place over the duration of the course rather than being the format for each topic. The NTL needs to consider group development and learning across the whole of the course, not just within each discussion.

There is some debate on the benefits, or lack thereof, of the NTL attempting to manage and moderate discussion. One risk is that the discussion becomes tutor-led. The converse is that the discussion strays off-topic. However, there is some agreement that if appropriate rules and instructions are in place, and if the pattern of communication is set and modeled early by the NTL, then students benefit from controlling the discussion and incorporating their own experience and goals (Moore \& Fetzner, 2004). A common and accepted finding is that setting quantitative measures of engagement limits discussion (Andresen, 
2009; Denne, 2005; Tu \& Corry, 2003; Zingaro \& Oztok, 2012). Some caution is required in the interpretation of the latter point. For example, setting a goal of two posts per week is not the same as saying students must make ' $\mathrm{X}$ ' number of contributions. This is the distinction between quantitative measures of engagement and goal setting.

An important and perhaps somewhat neglected consideration is the need to integrate discussion with other activities. This can be achieved through clear goal setting where goals include: interrogating the material; interaction with peers; discussions of a specific object (e.g. a paper/report/case); and the formation of critiques and 'hypotheses.' When the NTL posts a comment/discussion and/or poses questions, it's helpful to state whether an individual or group response is required. This opens up the possibility for public student-NTL debate and student-student debate (Aleksic-Maslac, Korican \& Njavro, 2007; Hirumi, $2002 a, 2002 b$ ). This is similar in function to the face-to-face lecturer engaging in debate and discussion during synchronous discussion.

\section{E. Conversational style}

The NTL's use of a conversational approach to students and within online interaction fosters high quality student contributions (Kanuka \& Anderson, 1998; York \& Richardson, 2012; Salmon, 2000) This means writing in conversational form and style; using personal anecdotes and affective verbal immediacy; the expression of appropriate emotion through the use of capitals, bold, italics; emoticons; and so on. The NTL should aim to set a tone of 'we're in this together' and be an active part of the community. Early communications should make use of plain language and over time the NTL should introduce the appropriate vocabulary for the course.

\section{F. Feedback}

Feedback tends to improve dialogue, especially when students know posts are being read by the NTL. This is true even if the NTL does not respond to each and every post. The level of dialogue seems to be higher when the NTL is involved. However, when the NTL leads the discussion student-student interaction decreases (Kanuka \& Anderson, 1998).

Thus far, no best fixed form of feedback has been identified in the literature. The key principles remain for timely and relevant feedback that meets students' communication needs and treats them as individuals. It should be personal, frequent and regular, and allow students to measure their progress.

\section{G. Questions}

The use of questions, including posing problems for solving, is a well-recognized learning tool and forms the spine of asynchronous discussion (Kanucka \& Anderson, 1998; York \& Richardson, 2012; Moore \& Fetzner, 2004; Salmon, 2000). There is agreement on several points in the literature. Perhaps the most difficult aspect for the NTL is allowing students to develop and design questions, including exam questions. That is not to say the students should design actual exam questions, but should be encouraged to knowingly construct exam type questions. Open-ended questions that ask students to evaluate and make connections, and which have multiple possible answers, develop higher cognitive functions (Andresen, 2009; Armstrong \& Thornton, 2012) They should be related to learning objectives and concepts and ideas in course reading as these questions generate more complex interaction between learners. When presenting situations, scenarios, case studies, and similar, questions should be designed that ask students what to do in such a situation, not what they think of the situation.

The use of bi- and tri-level discussion questions provides a useful structure for conceptualizing and designing questions (York \& Richardson, 2012). Level 1 questions are those where the answer can be found in course materials. Level 2 questions require students to relate materials to a personally relevant answer (i.e. one based on experience). Level 3 questions require students to find connections between course materials and broader historical, social, or cultural contexts.

As the community of inquiry develops it is suggested that, as with the development of the language of the 
community of practice, Level 1 questions are used early in the course discussion progressing to Level 3 questions later in the course.

\section{CONCLUSIONS}

The purpose of this paper was to address the question: as a tutor in an on-line asynchronous environment what necessary and sufficient behaviors can one enact to deliver high quality tuition? All other things being equal the facilitation of peer-peer discussion is considered the key factor.

Discussion may be the lynchpin of asynchronous tuition, but discussion on its own is not enough. Discussion is best considered as part of the collaboration process and production of artifacts in relation to the achievement of pedagogical outcomes. That is, discussion is necessary but is it not sufficient. Other factors, such as course design and goal setting, play an equally important role. However, with regard to these factors, researchers may benefit more from looking at the similarities between web-based tuition and face-to-face tuition than at the differences. This was the main reason for focusing on discussion in this short review. That is, we found such a high degree of common-sense similarity between most of the design and structural elements of face-to-face tuition and asynchronous tuition that our conclusion was to defer to the existing literature on optimal design and structure.

Overall we could find nothing to indicate distinct differences between course design and structure for asynchronous and synchronous learning. This included the reported finding that the reasons students drop out of asynchronous courses mirror the reasons students give when dropping out of synchronous courses. It is similarly logical to assume that problems such as non-participation and absenteeism are mirrored across both environments. That having been said, the importance of providing a social space was recognized as was the importance of introductions and engagement with and between students, as well as the importance and value of affective verbal immediacy-i.e., engaging with the text using a conversational style and with appropriate expression of emotion.

We suggest that discussion is a key factor in asynchronous learning, perhaps the key factor in producing high level pedagogical outcomes (Andresen, 2009; Brown, 2102; Dennen, 2005, 2008; Hew \& Cheung, 2003; Kear, 2004; Parisio, 2011; Aleksic-Maslac, Korican \& Njavro, 2007). However, it must be combined with the shared production of artifacts that relate directly to course objectives. The shared production of artifacts that relate directly to course objectives rely heavily on facilitated peer-peer discussion. The role of the NTL is critical in facilitating peer-peer discussion but fulfilling this role to its potential depends upon good design and course structure.

We acknowledge there are wider and deeper debates in the literature regarding the necessary and sufficient factors for successful implementation. The matter is not without controversy - the resolution of which depends largely on one's pedagogical philosophy. For example, is there a benefit in keeping the discussion controlled and focused on 'the topic' or is there a benefit in allowing and encouraging digression? Is there a benefit in bringing in personal experience or should the discussion be kept focused on the conceptual and cognitive elements? And so on. These elements are acknowledged and some consideration has been given to these above. 


\section{REFERENCES}

Andresen, M. A. (2009). Asynchronous discussion forums: success factors, outcomes, assessments, and limitations. Educational Technology \& Society, 12(1): 249-257.

Armstrong, A. and Thornton, N. (2012). Incorporating Brookfield's discussion techniques synchronously into asynchronous online courses. The Quarterly Review of Distance Education, 13(1): $1-9$.

Baumeister, R. F. and Leary, M. R. (1997). Writing Narrative Literature Reviews. Review of General Psychology, 1(3): 311-320.

Beaudin, B. P. (1999). Keeping online asynchronous discussions on topic. Journal of Asynchronous Learning Networks, 3(2): 41-53. from http://www.editlib.org/p/107297.

Brown, J. L. M. (2012). Online learning: A comparison of web-based and land-based courses. The Quarterly Review of Distance Education, 13(1): 39-42.

Cantor, J. A. (1992). Delivering Instruction to Adult Learners. Toronto: Wall \& Emerson.

Community Of Inquiry. Retrieved July 2013 from https://coi.athabascau.ca/

Crawley, A. and Fetzner, M. (2013). Providing service innovations to the student inside and outside of the online classroom: Focusing on student success. Journal of Asynchronous Learning Networks, 17(1): 7-12.

Dennen, P. V. (2005). From message posting to learning dialogues: Factors affecting learner participation in asynchronous discussion. Distance Education, 26(1): 127-148.

Dennen, P. V. (2008). Looking for evidence of learning: Assessment and analysis methods for online discourse. Computers in Human Behavior, 24: 205-219.

Fetzner, M. (2013). What do unsuccessful online students want us to know? Journal of Asynchronous Learning Networks, 17(1): 13-27.

Garrison, D. R., Clevenland-Innes, M. and Fung, T. S. (2010). Exploring causal relationships among teaching, cognitive and social presence: Student perceptions of the community of inquiry framework. The Internet and Higher Education, 13(1-2): 31-36.

Henri, F. (1995). Distance learning and computer-mediated communication: Interactive, quasiinteractive or monologue? In C. O’Malley (Ed.), Computer supported collaborative learning (pp. 145161). New York: Springer-Verlag.

Hew, K. F. and Cheung, W. S. (2003). Models to evaluate online learning communities of asynchronous discussion forums. Australian Journal of Educational Technology, 19(2): 241-259.

Higher Education Academy. Retrieved July 2013 from http://www.heacademy.ac.uk/

Hirumi, A. (2002a). A framework for analyzing, designing and sequencing planned e- learning interactions, Quarterly Review of Distance Education, 3(2): 141-60.

Hirumi, A. (2002b). The design and sequencing of e-learning interactions: a grounded approach, International Journal on E-Learning, 1(1): 19-27.Aleksic-Maslac, K., Korican, M. and Njavro, D. (2007). Important role of asynchronous discussion in e-learning system. International Conference on Engineering Education \& Research December 3-7, Melbourne, Australia. Retrieved June 2013 from http://bib.irb.hr/datoteka/468834.169.pdf.

Huang, X. and Hsiao. E-L. (2012). Synchronous and asynchronous communication in an online environment. The Quarterly Review of Distance Education, 13(1): 15-30.

Junk, V., Deringer, N, and Junk, W. ( 2011). Techniques to engage the online learner. Research in Higher Education Journal, 10: 1-15.

Jorczak, R. L (2011). An information processing perspective on divergence and convergence in collaborative learning. Computer-Supported Collaborative Learning 6(2): 207-221.

Kanuka, H. and Anderson, T. (1998). Online social interchange, discord, and knowledge construction. Journal of Distance Education, 13(1): 57-74. 
Kear, K. (2004). Peer learning using asynchronous discussion systems in distance education. Open Learning, 19(2): 151-164.

Kirby, J. R., Moore, P. J. and Schofield, N. J. (1998). Verbal and visual learning styles. Contemporary educational psychology, 13: 169-184.

Lee, S-M. (2014). The relationships between higher order thinking skills, cognitive density, and social presence in online learning. The Internet and Higher Education, 21: 41-52.

Lim, C. P. (2004). Engaging learners in online learning environments. TechTrends, 48(4): 16-23.

McGee, P. and Reis, A. (2012). Blended course design: A synthesis of best practice. Journal of Asynchronous Learning Networks, 16(4): 7-22.

Moore, J. C. and Fetzner, M. J. (2004). The road to retention: A closer look at institutions that achieve high course completion rates. Journal of Asynchronous Learning Networks, 13(3): 3-2.

Moule, P. (2007). Challenging the five-stage model for e-learning: a new approach. ALT-J, Research in Learning Technology, 15(1): 42-50.

Parisio, M. (2011). Engaging students in learning through online discussion: A phenomenographic study. Proceedings ascilite Hobart: Concise Paper. Retrieved June 2013 from http://www.ascilite.org.au/conferences/hobart11/downloads/papers/Parisio-concise.pdf

Pelz, B. (2004). (My) three principles of effective online pedagogy. Journal of Asynchronous Learning Networks, 8(3): 33-4.

Salmon, G. (2000). E-moderating: the key to teaching and learning online. London, Kogan Page.

Tu, C-H. and Corry, M. (2003). Designs, management tactics, and strategies in asynchronous learning discussions. The Quarterly Review of Distance Education, 4(3): 303-315.

Sloane Consortium. Retrieved July 2013 from http://sloanconsortium.org/

Ugoretz, J. (2005). Two roads diverged in a wood: Productive digression in asynchronous discussion. Innovate: Journal of Online Education, 1 (3). Retrieved June 2013

Vonderwell, S. (2003). An examination of asynchronous communication experiences and perspectives of students in an online course: a case study. Internet and Higher Education, 6: 77-90.

Wan, Y-m. (2008). Essential elements in designing online discussions to promote cognitive presence a practical experience. Journal of Asynchronous Learning Networks, 12(3-4): 157-177.

Winiecki, D. J. and Chyung, Y. (1998). Keeping the thread: Helping distance students and instructors keep track of asynchronous discussions. Distance Learning '98. Proceedings of the Annual Conference on Distance Teaching \& Learning. Retrieved June 2013 from http://files.eric.ed.gov/fulltext/ED422886.pdf.

York, C. S. and Richardson, J. C. (2012). Interpersonal interaction in online learning: Experienced online instructors' perceptions of influencing factors. Journal of Asynchronous Learning Networks, 16(4): 83-98.

Zingaro, D. and Oztok, M. (2012). Interaction in an asynchronous online course: A synthesis of quantitative predictors. Journal of Asynchronous Learning Networks, 16(4): 71-82. 